Article

\title{
Life Cycle Assessment of Flat Roof Technologies for Office Buildings in Israel
}

\author{
Svetlana Pushkar
}

Received: 27 October 2015; Accepted: 5 January 2016; Published: 8 January 2016

Academic Editors: Yasuhiro Fukushima, Yasushi Kondo, Shinsuke Murakami,

Masaharu Motoshita and Matthias Finkbeiner

Department of Civil Engineering, Ariel University, Ariel 40700, Israel; svetlanap@ariel.ac.il; Tel.: +972-3-9066-410

\begin{abstract}
The goal of the current study was to evaluate the environmental damage from three flat roof technologies typically used in Israel: (i) concrete, (ii) ribbed slab with concrete blocks, and (iii) ribbed slab with autoclaved aerated blocks. The roofs were evaluated using the Life Cycle Assessment (LCA) methodology. The Production and Construction (P and C), Operational Energy (OE), and Maintenance to Demolition (MtoD) stages were considered. The roofs were modeled based on an office building module located in the four climate zones of Israel, and the hierarchical ReCiPe2008 Life Cycle Impact Assessment (LCIA) method was applied. The percent difference of one, which is the default methodological option of ReCiPe2008, and an ANOVA of the six methodological options of ReCiPe2008 were used. The results revealed that (i) in a hot climate, the best roof technology can be selected by considering only the OE stage, whereas in a mild climate, both the $\mathrm{OE}$ and $\mathrm{P}$ and $\mathrm{C}$ stages must be considered; (ii) in a hot climate, the best roof technology is a concrete roof, but in a mild climate, the best options are ribbed slab roofs with concrete blocks and autoclaved aerated blocks; and (iii) the conjugation of ReCiPe2008 with a two-stage nested ANOVA is the appropriate approach to evaluate the differences in environmental damage in order to compare flat roof technologies.
\end{abstract}

Keywords: flat roof; LCA; ReCiPe2008; two-stage nested mixed ANOVA

\section{Introduction}

Life Cycle Assessments (LCAs) and Life Cycle Energy Analyses (LCEAs) of the building envelope are frequently presented in the current literature [1-3]. Both LCAs and LCEAs include the following building life stages: (i) Production and Construction (P and C), (ii) Operational Energy (OE) (for cooling, heating, and lighting needs), and (iii) Maintenance to Demolition (MtoD).

The relative contributions of the $\mathrm{P}$ and $\mathrm{C}$ and $\mathrm{OE}$ stages are known to cause the most damage to the environment [1,3] and are highly influenced by the following three factors: (i) The country-dependent local climate, (ii) the building technologies, and (iii) the primary fuel source for the OE production [1-3].

In Israel, only a few LCA and LCEA studies have been reported [4-8]. LCEAs performed with two life cycle stages, i.e., $\mathrm{P}$ and $\mathrm{C}$ and $\mathrm{OE}$, were reported by Huberman and Pearlmutter [5] and Huberman et al. [7]. Both of these studies considered a semi-arid climate (represented by Beer Sheva).

Huberman and Pearlmutter [5] studied wall components and suggested alternative masonry block types (i.e., stabilized soil blocks and fly-ash blocks) that could potentially replace the standard types of hollow concrete blocks and autoclaved aerated concrete blocks. Huberman et al. [7] considered roof components and suggested a simulation-based methodology for the optimization of a vaulted roof, and a typical flat concrete roof served as a comparison technology.

Huberman and Pearlmutter [5] converted the LCEA results into $\mathrm{CO}_{2}$ emissions by applying the average values of the conversion coefficients from the literature, e.g., $100 \mathrm{~kg}$ of $\mathrm{CO}_{2} / \mathrm{GJ}$ for the $\mathrm{P}$ and $\mathrm{C}$ stage and $50 \mathrm{~kg}$ of $\mathrm{CO}_{2} / \mathrm{GJ}$ for the $\mathrm{OE}$ stage. However, the primary energy sources for these 
coefficients were not specified, which made it difficult to perform a comparative analysis with other sources from the literature. Huberman et al. [7] reported their $\mathrm{OE}$ and $\mathrm{P}$ and $\mathrm{C}$ results in $\mathrm{GJ} / \mathrm{m}^{2}$, without consideration of the primary fuel source.

Pushkar et al. [4] evaluated all three stages of the LCA, i.e., P and C, OE, and MtoD. Pushkar [6] and Verbitsky and Pushkar [8] evaluated two stages of the LCA, i.e., P and C and MtoD. In all of these studies, the authors evaluated wall components.

Thus, an analysis of the literature regarding local Israeli LCEA and LCA studies indicated that wall components of the building envelope were primarily analyzed [4-6,8], whereas only one type of conventional flat roof (concrete) was evaluated [7].

However, regarding performance in the OE stage, the roof is the most sensitive component of the building envelope due to the direct exposure of the roof to the sky [9]. As a result, (i) on summer days, the roof is exposed to high-intensity sunlight, more so than any other envelope component, and (ii) on winter nights, due to increased contact with cool air, the roof is exposed to greater heat loss, in particular via long-wave radiation [9].

Napolano et al. [10] evaluated three flat roof technologies for a masonry structure located in the Mediterranean region of Italy: (i) Reinforced concrete joists with hollow clay blocks (RC flat roof), (ii) steel joists with a concrete slab (steel roof), and (iii) reinforced concrete joists with polystyrene panels (PS roof). The authors found it was not possible to determine the best environmental performance among the proposed roof technologies by considering the combined single score of all four damage categories of the IMPACT2002+ [Life Cycle Impact Assessment (LCIA)] method [11] because the best roof technology was different for each of the four damage categories. The RC flat roof was determined the best according to human health and resources; the PS flat roof, according to ecosystem quality; and the steel roof, according to climate change.

The ReCiPe2008 LCIA method [12] integrates three damage categories, i.e., human health, ecosystem quality, and resource use, into a single score evaluation without damaging the broad environmental evaluation. The ReCiPe2008 LCIA method accomplishes this by including three different views on environmental problems: Egalitarian, individualistic, and hierarchical perspectives [12]. Thus, the application of the ReCiPe2008 LCIA method [12] in conjunction with the two-staged nested ANOVA can solve such comparison problems [8]. A simple ANOVA tests several null hypotheses at the same time, while a two stage nested ANOVA should be used with nested (hierarchical) design structures. In this context, “...the inappropriate, simple ANOVA that ignored the sample structure resulted in grossly inflated Type I errors (rejecting a true null hypothesis of no difference in the means)" [13].

The aim of this study was to evaluate three flat roof technologies typically used for office buildings, including (i) concrete, (ii) ribbed slab with concrete blocks, and (iii) ribbed slab with autoclaved aerated blocks, in four different climate zones in Israel in order to determine the environmental impact of each technology.

\section{Methods}

\subsection{Research Framework}

LCAs were evaluated for the three building roof technologies typically used for office buildings in Israel: concrete, a ribbed slab with concrete blocks, and a ribbed slab with autoclaved aerated blocks. A building module $\left(50 \mathrm{~m}^{2}\right)$ of a typical multi-story [14] structure was adopted for this study. The examined module contained three internal walls (partitions) and one external wall. The dimensions of the module were $6.1 \mathrm{~m}$ in length, $3.7 \mathrm{~m}$ in height, and $8.2 \mathrm{~m}$ in depth.

Building module locations were selected to represent four climatic zones of Israel: A hot Mediterranean climate, represented by Tel-Aviv; a semi-arid climate, represented by Beer Sheva; a mild Mediterranean climate, represented by Jerusalem; and a desert climate, represented by Eilat [15]. 
The U.S. Department of Energy (DOE) building energy simulation program, EnergyPlus v.8.3 software, was used to calculate the operational energy requirements [16]. In this study, for the $\mathrm{OE}$ production stage, natural gas was applied as one of the major fuel types for electricity production in Israel [17]. The hierarchical ReCiPe2008 (with adaptations to v.1.06 2011) top-down method [12] was used for the LCA evaluation, and a two-stage nested ANOVA was used for the statistical evaluations.

\subsection{Design of the Three Flat Roofs According to Thermal Resistance and Structural Performance}

Following the approach suggested by Napolano et al. [10], the roofs of the module were designed in compliance with local construction technologies [18] (i) to meet the requirements for residential buildings according to the Standard of Israel (SI) 1045 [19] and (ii) to exhibit the same structural performance [20] (Figure 1). Completing a 2.5-cm (1-inch) thick concrete roof was not possible because the minimum thermal requirement must be fulfilled (according to SI 1045 [19]); therefore $5 \mathrm{~cm}$ of polystyrene (a 2-inch module standard [17]) was used. As a result, the concrete roof (A) U-value $\left(0.50 \mathrm{~W} / \mathrm{m}^{2} \cdot \mathrm{K}\right)$ differs from that of ribbed slab with concrete blocks $(B)\left(0.62 \mathrm{~W} / \mathrm{m}^{2} \cdot \mathrm{K}\right)$ and of ribbed slab with autoclaved aerated blocks $(\mathrm{C})\left(0.60 \mathrm{~W} / \mathrm{m}^{2} \cdot \mathrm{K}\right)$.

A


B

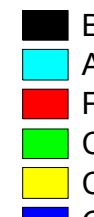

Bitumen sheets $(0.004 \mathrm{~m})$ Aerated concrete $(0.1 \mathrm{~m})$

Polystyrene $(0.025 \mathrm{~m})$ Concrete $(0.05 \mathrm{~m})$ Concrete block $(0.15 \mathrm{~m})$ Cement mortar $(0.01 \mathrm{~m})$

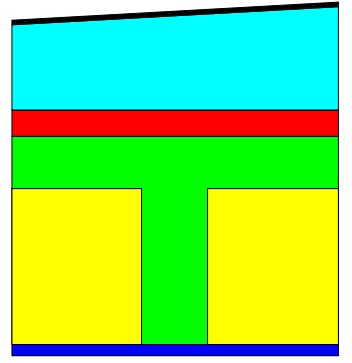

C



Figure 1. Layer sequence and thickness design of the three flat roof technologies: concrete (A); ribbed slab with concrete blocks (B); and ribbed slab with autoclaved aerated blocks (C).

Structural performance. To ensure the same structural performance for each of the three flat roofs, the steel quantity was evaluated by considering the bending moments from the total roof load/self-weight (dead load) on the concrete slab. The safety factor for the dead load was assumed as 1.4 [7], and the material properties included the steel density $\left(7858 \mathrm{~kg} / \mathrm{m}^{3}\right)$, the steel design strength (340 MPa), and the concrete design strength (21.5 MPa (B-42.5)).

\subsection{Environmental Evaluations}

The environmental framework of this study was selected according to the LCA method: (1) goal and scope (definition of the functional unit and the system boundaries), (2) Life Cycle Inventory (LCI) completion, (3) LCIA, and (4) interpretation [21].

Goal and scope. Three specific goals were of special interest: (i) To examine the contributions from the $\mathrm{P}$ and $\mathrm{C}, \mathrm{OE}$, and MtoD stages in the total LCA of the roof technologies, (ii) to determine the best roof technologies by applying the six methodological options in the ReCiPe2008 method, and (iii) to compare the two evaluation methods for the environmental damage of the roof technologies using ReCiPe2008 in conjunction with a two-stage nested mixed ANOVA via the simultaneous evaluation 
of the six methodological options of ReCiPe2008 and the percent difference using the single $\mathrm{h} / \mathrm{a}$ methodological option of ReCiPe2008.

According to ISO 14040 [21], "The primary purpose of a functional unit is to provide a reference to which the inputs and outputs are related". Thus, the functional unit (FU) was "one square meter of flat roof that serves 3.7 cubic meter of the building module $(1 \mathrm{~m}$ in length, $1 \mathrm{~m}$ in depth, and $3.7 \mathrm{~m}$ in height) with OE during 50 years". This FU allowed the consideration of the following building-related stages: $\mathrm{P}$ and $\mathrm{C}$ (production of building roof materials and components and transportation from the supplier to the construction site), $\mathrm{OE}$ (operational energy for module heating and cooling), and MtoD (transportation from the construction site to the disposal site and the disposal or recycling of roof materials and components).

LCI completion: OE evaluations. The three building modules (each designed with one of the three studied roofs) were modeled using the EnergyPlus v.8.3 software [16]. The occupancy hours were from 7:00 to 18:00, Sunday to Thursday. The air infiltration was set to 0.5 air changes/hr; DX coil systems were used for cooling with a $24^{\circ} \mathrm{C}$ set-point and heating with a $20^{\circ} \mathrm{C}$ set-point of the modules with a coefficient of performance (COP) of 3 . The design levels for the internal loads were set as follows: Four-person occupancy with an activity level at $100 \mathrm{~W}$, electric lights at $600 \mathrm{~W}$, electrical equipment at $800 \mathrm{~W}$, and clothing with winter at $1 \mathrm{Clo}$ and summer at $0.5 \mathrm{Clo}$. The detailed weather data for Tel-Aviv, Beer-Sheva, Jerusalem, and Eilat were collected through EnergyPlus Weather Data for Israel [16].

In a case where only the roof technologies differed and the remaining portions of the building were the same, Napolano et al. [10] suggested "to separate" the roof components from the remaining parts of the building. In this manner, in the OE stage, the transmission heat loss (in winter) and heat gain (in summer) needed to be computed through only the flat roof. Applying this approach [10] to derive the effect of the selected roof technology on the $\mathrm{OE}$, each of the three modules were simulated in two module locations: (i) On the upper level and (ii) on the intermediate level, and the difference between these locations (e.g., the roof $\mathrm{OE}$ ) was subsequently evaluated. OE was modeled with SimaPro v7.3 software [22] using the "Electricity, natural gas, at power plant/DE S" record.

LCI completion: $P$ and $C$ and MtoD evaluations. The LCI records for each of the three roof technologies were modeled with SimaPro v.7.3 software [22] using the Ecoinvent database (Table 1). The quantities of the composite materials for the concrete blocks and the autoclaved aerated blocks were obtained from a local supplier [6].

Table 1. $\mathrm{P}$ and $\mathrm{C}$ and MtoD stages: Data input from the Ecoinvent database (SimaPro v.7.3).

\begin{tabular}{|c|c|}
\hline Material & Data Source \\
\hline \multicolumn{2}{|l|}{$P$ and C Stage } \\
\hline Bitumen sheets & Bitumen, at refinery/CH S \\
\hline Aerated concrete and cement mortar & Cement mortar, at plant/CH S \\
\hline Concrete & Concrete, extracting, with de-icing salt contact, at plant/CH S \\
\hline Reinforcing steel & Reinforcing steel, at plant/RER S \\
\hline Transport & Transport, combination truck, average fuel $\mathrm{mix} / \mathrm{tkm} / \mathrm{RNA}$ \\
\hline Bitumen sheets & Disposal, building, bitumen sheet, to final disposal/CH S \\
\hline Aerated concrete, cement mortar, and autoclaved aerated block & $\begin{array}{l}\text { Disposal, building, cement (in concrete) and mortar, to final } \\
\text { disposal/CH S }\end{array}$ \\
\hline Polystyrene & $\begin{array}{l}\text { Disposal, building, polystyrene isolation, flame-retardant, to final } \\
\text { disposal/CH S }\end{array}$ \\
\hline Reinforcing steel & Disposal, building, reinforcement steel, to recycling/CH S \\
\hline Concrete & Disposal, building, reinforced concrete, to recycling/CH S \\
\hline
\end{tabular}

The Ecoinvent database included the associated transportation processes for raw building materials and component production. However, the local transportation distances from the supplier to the construction site ( $\mathrm{P}$ and $\mathrm{C}$ stage) and from the construction site to the disposal site (MtoD) were assumed. Israel is a small country; therefore, the average suitable transportation distances are relatively short [5] and depend on the amount of available building material and/or component supply centers. In particular, a 20-km distance was assumed for the concrete roof technology due 
to the restricted setting time of ready-mixed concrete. For the autoclaved aerated block, the aerated block, the polystyrene, and the bitumen sheets, $200 \mathrm{~km}$ was assumed due to a relativity low number of relevant manufacturers [6], while for the concrete block, $100 \mathrm{~km}$ was assumed as a result of the large number of manufacturers.

A relatively short distance $(50 \mathrm{~km})$ was assumed for the disposed materials/components compared to that for the recycled materials/components $(200 \mathrm{~km})$ because a much larger number of landfill sites are available in Israel compared to the number of recycling plants [23].

Construction and demolition steps were neglected due to their low contributions of environmental damage, e.g., $6 \%$, which stemmed from the production stage [5].

LCIA evaluation: ReCiPe2008 method. The LCI was converted to LCIA using the ReCiPe2008 method [12]. Within ReCiPe2008, the three different perspectives on environmental problems applied were egalitarian (considering all possible damages for a long period), individualistic (damages with only proven effects for a short period are evaluated), and hierarchical (a balance between the egalitarian and individualistic perspectives) [12].

Each perspective of ReCiPe2008 was weighted with (i) a set for the given methodological perspective (e.g., the egalitarian, individualistic, and hierarchical weighting data sets) and (ii) an average set. Consequently, ReCiPe2008 consist of six methodological options: egalitarian/egalitarian (e/e), egalitarian/average (e/a), hierarchical/hierarchical (h/h), hierarchical/average (h/a), individualistic/individualistic (i/i), and individualistic/average (i/a) [12].

According to Goedkoop and Spriensma [24], (i) the default h/a option should be used for the environmental evaluation because the $\mathrm{h}$ / a option accounts for a balance between short and longterm emissions effects with consensus regarding relevant damage, and (ii) if two similarly produced materials are compared, then even small differences, such as $10 \%$ to $20 \%$ of the compared $\mathrm{h} / \mathrm{a}$ scores, indicate that the materials differ. However, when two completely different materials are compared, only a much larger difference, $100 \%$ or greater, is sufficient to conclude that these materials differ significantly.

The simultaneous use of the six methodological options can aid in mitigating the uncertainty of the LCIA method [8]; however, it is difficult to decide whether the building components are completely different or similar (e.g., in the case of a ribbed slab with concrete blocks and a ribbed slab with autoclaved aerated blocks).

In this context, the three perspectives of ReCiPe2008 can be considered with two weighting sets: An average set (e/a, h/a and i/a) and a particular set (e/e, h/h and i/i) and, as a consequence, their design structure can be defined as a hierarchical design structure [6]. Therefore, the use of hierarchical ANOVAs allows the simultaneous evaluation of the six methodological options of ReCiPe2008 [8].

\subsection{Statistical Aanalysis}

Datasets from the three roof technologies were log transformed prior to analysis. A two-stage, nested, fixed, random ANOVA was used to compare the environmental damage based on simultaneous evaluation with the six methodological options of ReCIPe2008 [8]. Additionally, the percent difference between the two values of environmental damage (ED), as evaluated with one methodological option (h/a) of ReCiPe2008, was calculated using the ratio $\mathrm{ED}_{\max } \times 100 / \mathrm{ED}_{\min }-100$.

$p$-values were evaluated according to three-valued logic: "It seems to be positive", "it seems to be negative", and "judgment is suspended" [25], i.e., there seems to be a roof technology difference, there does not seem to be a roof technology difference, and judgment is suspended with respect to the roof technology difference. 


\section{Results and Discussion}

3.1. Preparatory Events: Quantities of the Roof Components and the Effect of Selected Flat Roof Technologies on the Energy Requirements for Space Conditioning Building Modules

The quantities of the roof components for the three flat roof technologies were evaluated, and the results are presented in Tables 2 and 3 .

Table 2. Quantities of the roof components designed for the three flat roof technologies.

\begin{tabular}{|c|c|c|c|}
\hline Roof Components & $A\left(\mathrm{~kg} \cdot \mathrm{m}^{-2}\right)$ & $B\left(\mathrm{~kg} \cdot \mathrm{m}^{-2}\right)$ & $\mathrm{C}\left(\mathrm{kg} \cdot \mathrm{m}^{-2}\right)$ \\
\hline Bitumen & 4.8 & 4.8 & 4.8 \\
\hline Aerated concrete & 80 & 80 & 80 \\
\hline Polystyrene & 1.5 & 0.75 & 0.75 \\
\hline Concrete (A), concrete block (B), aerated block (C) & 336 & 120 & 60 \\
\hline Cement mortar & 18 & 18 & 18 \\
\hline Total roof self-weight & 440 & 344 & 284 \\
\hline
\end{tabular}

Note: concrete (A), ribbed slab with concrete blocks (B), and ribbed slab with autoclaved aerated blocks (C)

Table 3. Quantities of the cement and steel designed for the three flat roof technologies.

\begin{tabular}{|c|c|c|c|}
\hline Building Material & $A\left(\mathrm{~kg} \cdot \mathrm{m}^{-2}\right)$ & $B\left(\mathrm{~kg} \cdot \mathrm{m}^{-2}\right)$ & $\mathrm{C}\left(\mathrm{kg} \cdot \mathrm{m}^{-2}\right)$ \\
\hline Evaluated steel quantity & 9.8 & 5.3 & 4.3 \\
\hline Evaluated cement quantity & 50.4 & 10.6 & 3.2 \\
\hline
\end{tabular}

Note: concrete (A), ribbed slab with concrete blocks (B), and ribbed slab with autoclaved aerated blocks (C).

The effects of the selected flat roof technology on the OE stage of building modules located in Tel Aviv, Beer Sheva, Jerusalem, and Eilat are presented in Table 4.

Table 4. Effect of the selected flat roof technology on the Operational Energy (OE) requirements for space conditioning building modules in four separate climate zones in Israel.

\begin{tabular}{ccccc}
\hline \multirow{2}{*}{ Roof Technology } & \multicolumn{4}{c}{ Annual Heating and Cooling Energy $\mathbf{( k W h \cdot \mathbf { m } ^ { - 2 } \cdot \mathbf { 5 0 } \text { year) }}$} \\
\cline { 2 - 5 } & Tel Aviv & Beer Sheva & Jerusalem & Eilat \\
\hline A & 134.5 & 154.1 & 81.5 & 261.8 \\
B & 163.9 & 183.3 & 88.9 & 329.1 \\
C & 166.5 & 186.6 & 93.6 & 316.8
\end{tabular}

Note: Concrete (A), ribbed slab with concrete blocks (B), and ribbed slab with autoclaved aerated blocks (C). OE was evaluated as an average of four building evaluations per cardinal direction of north, east, south, and west (SI 5282 [14])

\subsection{Total LCA and the Shares of the P and C, OE, and MtoD Stages of the Flat Roof Technologies (Evaluated} via the Default H/A Methodological Option of ReCiPe2008) under Climate Factors

The portion of the $\mathrm{P}$ and $\mathrm{C}$ environmental damage in Jerusalem (nearly $50 \%$ of the total LCA) (Figure 2) correlates well with the results obtained in the P and C stage for the RC and PS flat roofs in Napoli, Italy [10]. A large portion (50\%-80\%) of the OE stage stemmed from the high cooling demands of the office building type due to the high internal load (people, light, and equipment). The OE damage results are in compliance with the highest number of cooling degree-days in Eilat (1404), the lowest number of cooling degree-days in Jerusalem (174), and the intermediate numbers of cooling degree-days in Tel Aviv (308) and Beer Sheva (455) [17]. 


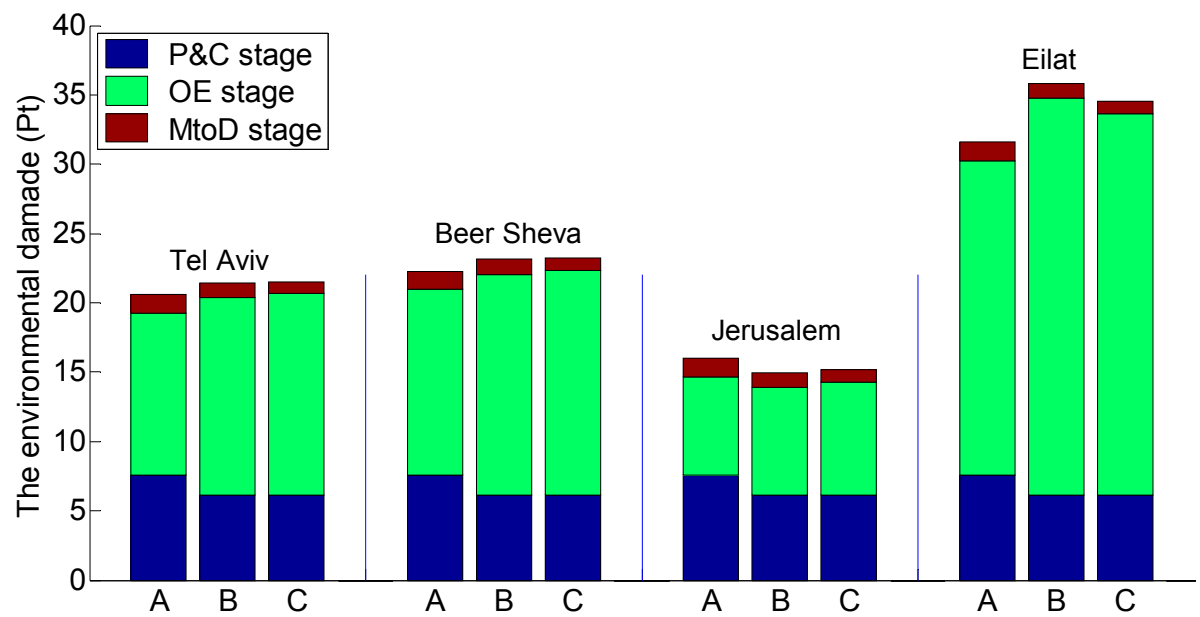

Figure 2. Environmental damage $(\mathrm{Pt})$ of the Production and Construction $(\mathrm{P}$ and $\mathrm{C})$ stage, Operational Energy (OE) stage, and Maintenance to Demolition (MtoD) stage in an office building module with a natural gas source for OE, located in Tel-Aviv, Beer-Sheva, Jerusalem, or Eilat. The three evaluated flat roof technologies were concrete (A); ribbed slab with concrete blocks (B); and ribbed slab with autoclaved aerated blocks $(\mathrm{C})$. The environmental damage was evaluated with the default $\mathrm{h} / \mathrm{a}$ option of ReCiPe2008.

\subsection{Ranking the Flat Roof Technologies in Israel according to an Analysis of the Six Methodological Options of the ReCiPe2008 Method}

The total LCA of the flat roof technologies was evaluated via all methodological options of ReCiPe2008 (Figure 3). The ranking of the three roofs in ascending order of the total LCA are as follows:
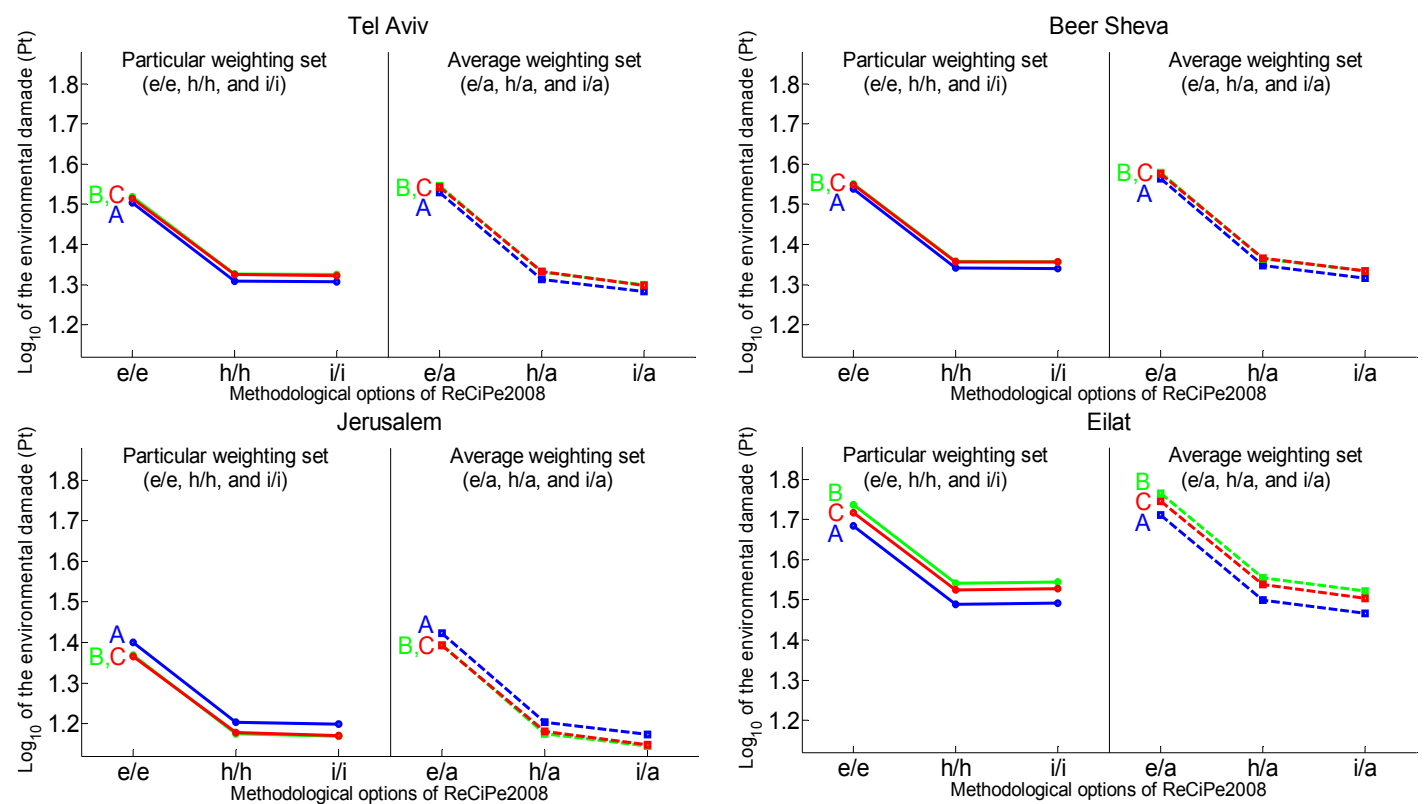

Figure 3. Tel Aviv, Beer Sheva, Jerusalem, and Eilat: LCAs of the roofs of an office building module with a natural gas energy source for operational energy needs. The three evaluated flat roof technologies were concrete (A); ribbed slab with concrete blocks (B); and ribbed slab with autoclaved aerated blocks (C). The LCA $(\mathrm{Pt})$ was evaluated with two sets of methodological options: The average weighting set (e/a, h/a, and i/a) and the particular weighting set (e/e, h/h, and i/i). 
(i) Tel Aviv, Beer Sheva, and Eilat-First, concrete; second, ribbed slab with autoclaved aerated blocks, and third, ribbed slab with concrete blocks. These results were revealed under all options. Therefore, in these cases, evaluations with Recipe2008 are sufficient, and complimentary analysis by ANOVA is unnecessary.

(ii) Jerusalem-First and second ribbed slab with concrete blocks and ribbed slab with autoclaved aerated blocks. These roofs altered their positions from first to second under different methodological options (e/e and e/a: ribbed slab with autoclaved aerated blocks in the first position and ribbed slab with concrete blocks in the second position; $\mathrm{i} / \mathrm{i}, \mathrm{i} / \mathrm{a}, \mathrm{h} / \mathrm{h}, \mathrm{h} / \mathrm{a}$ : ribbed slab with concrete blocks in the first position and ribbed slab with autoclaved aerated blocks in the second position); thus, the crossover between the results of these two roofs under the methodological options of ReCiPe2008 was revealed. Therefore, in this case, using the ReCiPe2008 method with an ANOVA, in which the six methodological options of ReCiPe2008 are simultaneously evaluated, is deemed necessary.

\subsection{LCA of Flat Roof Technologies: (i) The P-value via the Hierarchical Design Structure of ReCiPe2008 and} (ii) the Percent Change via the h/a Option of ReCiPe2008

In all climate zones (Tel Aviv, Beer Sheva, Jerusalem, and Eilat), the results of the $p$-value analysis (ANOVA) of ReCiPe2008 were not always in agreement with the results from the percent difference for the $\mathrm{h}$ / a option of ReCiPe2008 (Table 5), although the $\mathrm{h} / \mathrm{a}$ is recommended as the default option [24]. For example, in Jerusalem, according to the ANOVA ( $p$-value $=0.0014$; six methodological options used), the concrete roof and the ribbed slab with autoclaved aerated blocks roof produce a significant difference in environmental damages, but according to the percent difference $(6.2 \%-\mathrm{h} / \mathrm{a}$ option), the the environmental damages of these technologies were the same.

Table 5. Office building module with the natural gas option in four separate climate zones in Israel.

\begin{tabular}{|c|c|c|c|c|}
\hline Climate Zone & Roof Technology & A & B & $\mathrm{C}$ \\
\hline \multirow{3}{*}{ Tel Aviv } & $\mathrm{A}$ & $x$ & $0.0088^{a}(4.3)$ & $0.0201^{\mathrm{c}}(3.8)$ \\
\hline & B & & $x$ & $0.4466^{\mathrm{b}}(0.4)$ \\
\hline & $\mathrm{C}$ & & & $x$ \\
\hline \multirow{3}{*}{ Beer Sheva } & A & $x$ & $0.020^{\mathrm{c}}(4.0)$ & $0.034^{\mathrm{c}}(3.5)$ \\
\hline & B & & $x$ & $0.7892^{\mathrm{b}}(0.4)$ \\
\hline & $\mathrm{C}$ & & & $\mathrm{X}$ \\
\hline \multirow{3}{*}{ Jerusalem } & A & $X$ & $0.0005^{a}(6.8)$ & $0.0014^{a}(6.2)$ \\
\hline & $\mathrm{B}$ & & $X$ & $0.3225^{\mathrm{b}}(0.7)$ \\
\hline & $\mathrm{C}$ & & & $x$ \\
\hline \multirow{3}{*}{ Eilat } & A & $x$ & $0.0056^{\mathrm{a}}(12.9)$ & $0.0115^{a}(8.7)$ \\
\hline & B & & $x$ & $0.0634^{\mathrm{c}}(3.9)$ \\
\hline & $\mathrm{C}$ & & & $\mathrm{X}$ \\
\hline
\end{tabular}

${ }^{a}$ Font style is bold-Seems to be positive; ${ }^{b}$ Font size is ordinal-Seems to be negative; ${ }^{c}$ Font style is italic-Judgment is suspended. The three evaluated flat roof technologies are concrete (A), ribbed slab with concrete blocks (B), and ribbed slab with autoclaved aerated blocks (C). The $p$-value $(P)$ and percent differences $(\%)$ are presented in the table as $P(\%)$ of the pairing differences in the three roof technologies as a function of the total LCA evaluated with ReCiPe2008, two-stage nested mixed balanced ANOVA, degrees of freedom ( $d f$ ) $\mathrm{df}_{1}=1 \mathrm{df}_{2}=2$, and probability resulting from a significance test $(P)$.

\section{Conclusions}

In Tel Aviv, Beer-Sheva, and Eilat, selection of the best flat roof technologies should be performed with consideration of only the OE stage. However, in Jerusalem, only considering the OE stage cannot serve as an appropriate environmental measurement because the $\mathrm{P}$ and $\mathrm{C}$ and MtoD of the flat roof must also be evaluated.

Selection of the best flat roof technology is influenced by the climate zone; therefore, in Tel Aviv, Beer-Sheva, and Eilat, the concrete flat roof technology is preferred, while, in contrast, either of the two 
flat roof technologies (ribbed slab with concrete blocks and ribbed slab with autoclaved aerated blocks) is preferred in Jerusalem. To determine the equivalence of the ribbed slab with concrete blocks and the ribbed slab with autoclaved aerated blocks roof technologies in Jerusalem, ReCiPe2008 alone is not enough and should be complimented by ANOVA.

To evaluate the differences in the environmental damage between two flat roof technologies in all climate zones of Israel, evaluations performed using the ReCiPe2008 method with a two-stage nested mixed ANOVA (in which the six methodological option of ReCiPe2008 are simultaneously evaluated) should be used rather than the percent difference of a single methodological option (h/a) of ReCiPe2008.

Acknowledgments: The author is grateful to Oleg Verbitsky for his help with the statistical analysis and to three anonymous reviewers for their helpful comments.

Conflicts of Interest: The author declare no conflict of interest.

\section{References}

1. Ramesh, T.; Prakash, R.; Shukla, K.K. Life cycle energy analysis of buildings: An overview. Energy Build. 2010, 42, 1592-1600. [CrossRef]

2. Karimpour, M.; Belusko, M.; Xing, K.; Bruno, F. Minimising the life cycle energy of buildings: Review and analysis. Build. Environ. 2014, 73, 106-114. [CrossRef]

3. Ibn-Mohammed, T.; Greenough, R.; Taylor, S.; Ozawa-Meida, L.; Acquaye, A. Operational vs. embodied emissions in buildings-A review of current trends. Energy Build. 2013, 66, 232-245. [CrossRef]

4. Pushkar, S.; Becker, R.; Katz, A. A methodology for design of environmentally optimal buildings by variable grouping. Build. Environ. 2005, 40, 1126-1139. [CrossRef]

5. Huberman, N.; Pearlmutter, D. A life-cycle energy analysis of building materials in the Negev desert. Energy Build. 2008, 40, 837-848. [CrossRef]

6. Pushkar, S. Using Eco-Indicator 99 to evaluate building technologies under LCA uncertainties. J. Archit. Eng. 2014. [CrossRef]

7. Huberman, N.; Pearlmutter, D.; Gal, E.; Meir, I.A. Optimizing structural roof form for life-cycle energy efficiency. Energy Build. 2015, 104, 336-349. [CrossRef]

8. Verbitsky, O.; Pushkar, S. Eco-Indicator 99, ReCiPe, and ANOVA for evaluating building technologies under LCA uncertainties. Environ. Eng. Manag. J. 2015. accepted.

9. Lechner, N. Heating, Cooling, Lighting: Sustainable Design Methods for Architects; Wiley \& Sons, Inc.: Hoboken, NJ, USA, 2014.

10. Napolano, L.; Menna, C.; Asprone, D.; Prota, A.; Manfredi, G. Life cycle environmental impact of different replacement options for a typical old flat roof. Int. J. Life Cycle Assess. 2015, 20, 694-708. [CrossRef]

11. Jolliet, O.; Margni, M.; Charles, R.; Humbert, S.; Payet, J.; Rebitzer, G.; Rosenbaum, R. IMPACT 2002+: A new life cycle impact assessment methodology. Int. J. Life Cycle Assess. 2003, 8, 324-330. [CrossRef]

12. Goedkoop, M.; Heijungs, R.; Huijbregts, M.; de Schryver, A.M.; Struijs, J.; van Zelm, R. ReCiPe 2008: A Life Cycle Impact Assessment Method which Comprises Harmonized Category Indicators at the Midpoint and the Endpoint Level. First Edition; Report I: Characterisation. Available online: http://www.leidenuniv.nl/cml/ssp/publications/recipe_characterisation.pdf (accessed on 20 October 2015).

13. Picquelle, S.J.; Mier, K.J. A practical guide to statistical methods for comparing means from two-stage sampling. Fish. Res. 2011, 107, 1-13. [CrossRef]

14. The Standards Institution of Israel. Energy Rating of Building: Office Buildings. 2011. Available online: http://www.energianews.com/newsletter/files/667dd7b1c8625f5db67a0fd20ecf35ce.PDF (accessed on 16 November 2015). (In Hebrew)

15. The Standards Institution of Israel. Standard 1045, Part 10: Thermal Insulation of Buildings: Classification of Settlements According to Climatological Regions; The Standards Institution of Israel: Tel Aviv, Israel, 2010.

16. EnergyPlus. Engineering Reference, the Reference to EnergyPlus Calculations. Available online: https://energyplus.net/sites/default/files/pdfs_v8.3.0/EngineeringReference.pdf (accessed on 5 January 2015). 
17. Friedman, C.; Becker, N.; Erell, E. Energy retrofit of residential building envelopes in Israel: A costbenefit analysis. Energy 2014, 77, 183-193. [CrossRef]

18. Pearlmutter, D.; Erell, E.; Meir, I.A.; Etzion, Y.; Rofe, Y. Guidance to Bio-climatic Building in Israel; Israel Ministry of National Infrastructures: Jerusalem, Israel, 2010. (In Hebrew)

19. The Standards Institution of Israel. Thermal insulation of buildings: Office buildings. 2010. Available onlie: http:/ / www.sviva.gov.il/English/env_topics/GreenBuilding/Pages/GreenBuildingStandards.aspx\#GovX ParagraphTitle3 (accessed on 20 October 2015).

20. The Standards Institution of Israel. SI 466, Israeli Standard, Part 1-Concrete Code: General Principles; The Standards Institution of Israel: Tel Aviv, Israel, 2003.

21. International Organization for Standardization. Environmental Management_Life Cycle Assessment-Principles and Framework; ISO 14040; International Organization for Standardization: Geneva, Switzerland, 2006.

22. SimaPro 7, version 7.3.3; ReCiPe2008 v. 1.06; PRé Consultants: Amersfoort, Netherlands, 2011.

23. Israel Ministry of Environmental Protection. "Waste sites and Recycling companies". 2015. Available online: http:/ /www.sviva.gov.il/subjectsenv/waste/constructionwaste/documents/constructionwaste-sitelist 2015.pdf (accessed on 7 January 2016). (In Hebrew)

24. Goedkoop, M.; Spriensma, R. The Eco-indicator 99, a Damage Oriented Method for Life Cycle Impact Assessment, Methodology Annex. Available online: https://www.pre-sustainability.com/ download/EI99_annexe_v3.pdf (accessed on 5 January 2016).

25. Hurlbert, S.H.; Lombardi, C.M. Final collapse of the Neyman-Pearson decision theoretic framework and rise of the neoFisherian. Ann. Zool. Fenn. 2009, 46, 311-349. [CrossRef]

(c) 2016 by the author; licensee MDPI, Basel, Switzerland. This article is an open access article distributed under the terms and conditions of the Creative Commons by Attribution (CC-BY) license (http://creativecommons.org/licenses/by/4.0/). 